\title{
The Impact of the Global Crisis on External Communication in the Circular Economy
}

\author{
Jarmila Šalgovičová ${ }^{1, *}$ and Peter Ušák $^{2}$ \\ ${ }^{1}$ University of SS Cyril and Methodius in Trnava, Faculty of Mass Media Communication, \\ Deparment of Marketing Communication, Námestie J.Herdu 2, 91701 Trnava, Slovakia \\ ${ }^{2}$ University of SS Cyril and Methodius in Trnava, Faculty of Mass Media Communication, \\ Deparment of Marketing Communication, Námestie J.Herdu 2, 91701 Trnava, Slovakia
}

\begin{abstract}
.
Research background: We are in a period when the society got into a global crisis. The main trigger was the arrival of a worldwide coronavirus pandemic. The European Union is responding and sending an unprecedented rescue package to help the economies of the individual Member States. In a short time, entrepreneurs are forced to drastically change their strategies to ensure a basic survival in the market. Under the influence of globalization in connection with the crisis, companies are under increasing pressure to base their business activities on the principles of the circular economy.

Purpose of the article: The aim of the paper is to analyze the external communication in a particular multinational company and to point out the advantages of applying the principles of the circular economy, used in the conditions of the global economic crisis.

Methods: We will analyze theoretical knowledge from domestic and foreign authors. We will analyze external data that will provide us with information about the tools of external communication that are used in the standard period and we will compare them with the external communication used in the current crisis period.

Findings \& Value added: The contribution of the paper is in pointing to the fact that external communication and communication tools tend to change depending on the specific situation in which the company finds itself, how companies had to adjust their external communication depending on the pandemic in which the whole society found itself.
\end{abstract}

Keywords: Corporate Social Responsibility; Circular Economy; Crisis; External communication

JEL Classification: Q01; Q5

* Corresponding author: j.salgovicova@,gmail.sk 


\section{Introduction}

In February 2020, the atmosphere in Slovakia was very tense. Parliamentary elections were approaching and they felt they would be important. The media focused on political discussions, and elections became the number one topic in conversations between ordinary people. At the end of February, the winners and losers were decided, but the media continued to live on the subject. At that time, there was already a big problem in Italy. About a week after the parliamentary elections, information about a new virus that has entered Europe comes to the fore in the course of hours. The situation is deteriorating sharply in the coming days, information about hundreds of deaths will force individual states to close their borders, declare a state of emergency in the country, introduce national quarantines, and so on. Under this pressure, the economy begins to collapse and markets almost freeze. There is a crisis in Europe, the effects of which are compared to the leaders of individual Member States to the Second World War. The virus continues to spread to the United States, South America, and multinationals are beginning to realize that we are falling into a global crisis. Our area of interest is socially responsible business as part of the circular economy. We realize that the current situation we are in is completely different from the "standard" to which entrepreneurs are accustomed. The aim of the paper is to analyze and compare external communication in connection with the social responsibility of VUB Bank before and after the pandemic. As an example, we will mention commercials. We will try to clarify how and why consumers' shopping behavior has changed and how they perceive social responsibility.

\section{Literature review}

\subsection{Corporate social responsibility as a part of circular economy}

A circular economy $(\mathrm{CE})$ can be defined as an economic model aimed at the efficient use of resources through waste minimization, long-term value retention, reduction of primary resources, and closed loops of products, product parts, and materials within the boundaries of environmental protection and socioeconomic benefits. A CE has the potential to lead to sustainable development, while decoupling economic growth from the negative consequences of resource depletion and environmental degradation $[1,2,3]$.

In the pre-crisis period, the vast majority of companies presented their positive approach to adhering to the principles of the circular economy. However, there seem to be businesses that either do not understand the current situation or even underestimate it. A socially responsible business is not only aimed at maximizing profit in the short term, but its objectives are based on the needs of the internal and external environment and include the social and environmental aspects of the business. Rather, such an organization has objectives that contribute to long-term 
profit-making and long-term development of the whole society. Making profit is not the only goal of such an organization. Due to the growing importance of human resources, which represent the key capital of a company, the effort to harmonize employee relations is becoming increasingly important, whereas securing such tasks becomes a priority for companies that are serious about socially responsible business [4]. It follows that if a company perceives the values of social responsibility as really important, then it can use the period of crisis and show the public that its business is based on real values. It is also related to the long-term perception of goals in general, so the period of crisis does not pose a threat in this respect. Consumer behavior is also changing in connection with the changes that the whole society has undergone in the last period. Successfully addressing unsustainable consumer behavior still remains one of the key challenges for sustainable development [5]. For our research, we used the Kantar survey [6], called the Covid-19 Barometer, which looked at changes in consumer behavior during the pandemic and was conducted in several countries. of the world. The following graph shows an interesting fact that emerged from the survey. In general, people are more than concerned about the societal effects of the current crisis.

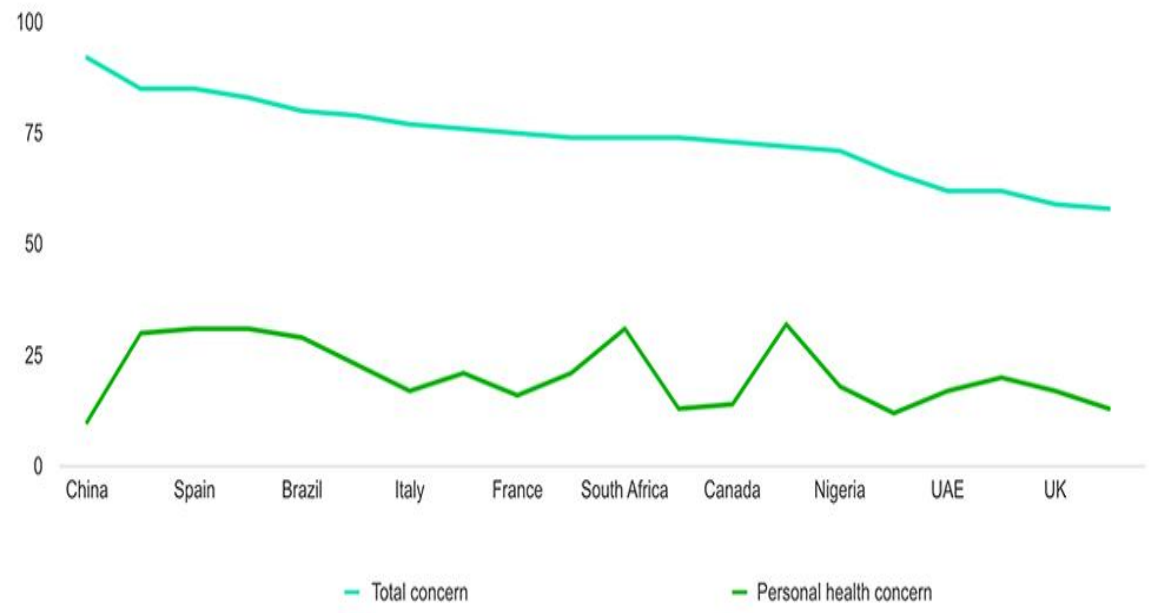

Fig. 1. The societal effects of the current crisis. [6]

The fact that people prefer societal interests over their personal means that they are directly interested in the topic of social responsibility. In their purchasing decisions, they are therefore likely to make more and more decisions based on how they perceive the product manufacturer from the point of view of socially responsible business. Covid-19 therefore presents several challenges for companies. Some companies have tried to profit from this crisis. To curb the potential benefits, in the United Kingdom, for example, a competition authority, called the 'Competition and Markets Authority', has been set up to take action against companies benefiting from the current crisis by inflating prices or introducing products [7]. 


\subsection{Globalization in crisis}

Money and finance are the bloodstream of the global economy. Without money, the global economy as we know it could not exist [8]. All transactions between individuals, companies and countries use a certain type of payment unit and this cash flow must be reliable and smooth. This is important for the functioning of the global economy [9]. Without a functioning and reliable payment system, the global economy would be at risk, even impossible [10]. Globalization is a long and complex process. This is reflected in the economics, culture and politics. The movement of goods across the planet is expanding and accelerating through globalization. The International Monetary Fund cites international trade as one of the main aspects of globalization. The well-known "think global, act local" is becoming more popular among consumers [11]. It could be the answer to mutual conscious cooperation between companies and consumers. Becoming a global citizen is conscious and transformative learning. It needs to be accepted, developed and practised [12]. The current crisis situation has shown the extent to which global economies are interconnected, but also the economies of individual Member States of the European Union. In Slovakia, we are in an extremely difficult situation, when the second wave of the pandemic is beginning and, as it turns out, it will most likely hit the economy even more than the first wave, and therefore several experts are currently pointing to the need for greater self-sufficiency.

\subsection{External communication}

Communication plays an irreplaceable role in the performance of the managerial profession. If we look at any definition or the basic knowledge of management theory, we will find that we encounter it at every step. An effective risk communication, in general, means that all related risk messages can be presented and shared to participants in a risk communication process openly and timely, aiming to rectify the knowledge gap between the originators of information and those receiving the information, and adjust the public's behavior to cope with the risk proactively $[13,14]$.

\subsection{Advertising in crisis}

For our research and to better understand how consumers perceive advertising as a tool for external communication, we used the results of the Kantar survey [www.kantar.com/campaigns/covid-19-barometer]. In a sample of more than 25,000 respondents in 30 countries, it measured consumer attitudes, media habits, the impact on shopping attitudes and also found out what consumers expect from brands. We talked about how consumers prefer social interests to their own, and what that means for the area of socially responsible business. The following graph shows us the results of a survey in Slovakia, which shows the views of respondents on what they should do in the current situation. Only 16 percent said companies should stop advertising. 
What should companies do now?

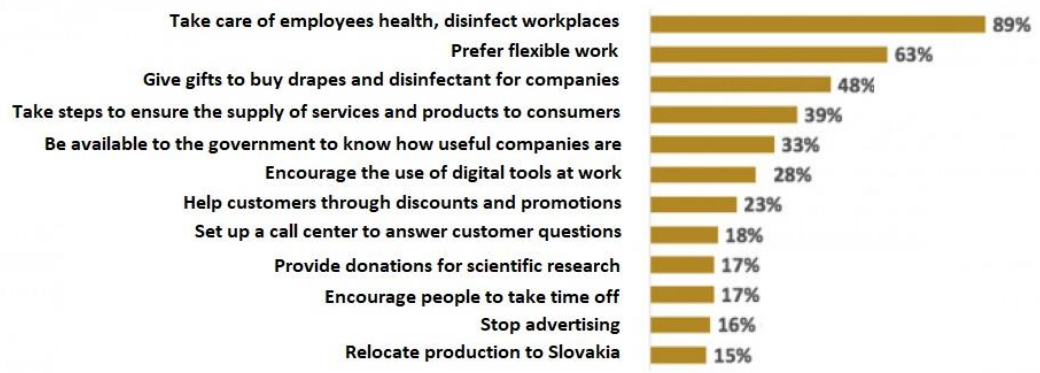

Fig. 2. The steps to be taken in this situation. [6]

The fact that people generally do not reject advertising is an opportunity to change advertising tactics. Consumers and their shopping behavior are changing rapidly. Society is in a state of uncertainty, so consumers will be looking for something they can rely on, something they can trust, something that will provide a sense of security and safety. A good choice would be a new, honest advertising strategy that respects the current situation and respects the principles of socially responsible business and the circular economy. Green advertising influences individual attitudes towards advertising and their intention to be environmentally friendly [15].

\section{Methods}

To better understand the context, we analyzed the attitudes of domestic and foreign authors on the topics of socially responsible business, we used the global survey of the agency Kantar and we found several interesting facts. We also dealt with globalization in times of crisis and analyzed external communication with a focus on advertising. Based on a case study, we compared the change in advertising strategy before and after the pandemic. We named how a change in advertising strategy is related to a change in consumer behavior.

\section{Case study}

The case study provides us with information on how VUB Bank reacted to the arrival of the pandemic from the point of view of advertising. We will analyze advertising spots, so how the bank communicated in the period before the crisis and after its onset. We decided on VUB bank on the basis of a brief analysis of advertising spots from several competing banks and we assessed that it would serve as our best example. VUB is the second largest bank in Slovakia and at the same time the only one licensed to provide a full range of banking services. According to current data on the rating for long-term deposits, it is A2, for short-term deposits it is P-1 with a negative outlook [16]. It is a company that has committed itself to doing 
business responsibly. Social responsibility is based mainly on ethics and transparency. It combines its activities and interests with ethical values beyond the framework of the law. He attaches importance to a comprehensive approach to business, which is supported by transparent actions of VUB bank in relation to all partners [17].

The first commercial we analyzed was broadcast in the period just before the crisis. Thematically, it deals with investing in mutual funds. Advertising communication is traditional, there is no indication that any change is imminent. The second commercial we analyzed responds to the sharp decline in markets due to the bad situation in Europe and deteriorating worldwide. At this point, crisis management responded by changing its advertising strategy, and the message of advertising is that people should not panic from declining markets and withdraw their invested money from funds. It is informative in nature, providing information on the benefits of long-term investment and the benefits of investing in times of market decline. Another commercial already accurately captures the situation and responds to market requirements. We talked about the fact that in times of crisis, people prefer social values over their own and wait for a sense of security and belonging. The content of this advertisement is the message that even in a very difficult situation, in which we all find ourselves, VUB Bank stands behind its clients, moreover, it was communicated in a way that the bank thinks society-wide. Then in a few days comes the second version of the ad with the same message, but a changed visual page.

The following images show the first two commercials we analyzed. The strategy is focused on investing, although the second spot already shows the response to the crisis.

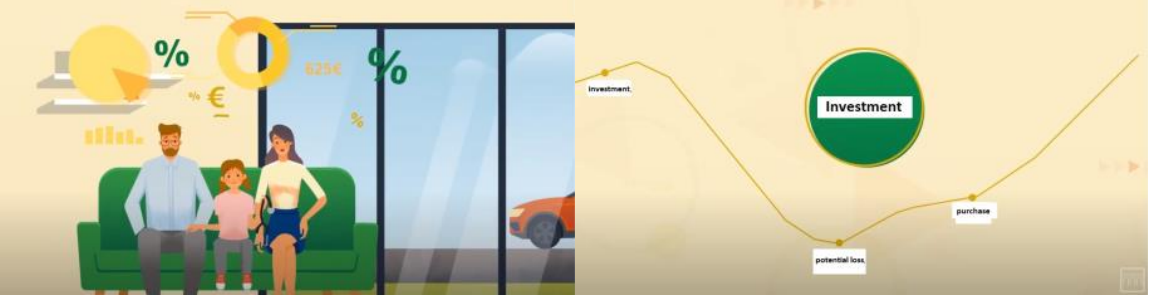

Fig. 3. The first analyzed commercial.

The following pictures show commercials, the first of which is a clear response of crisis management to the crisis. The second picture shows a spot that is current and responds to green grants from European Union funds.

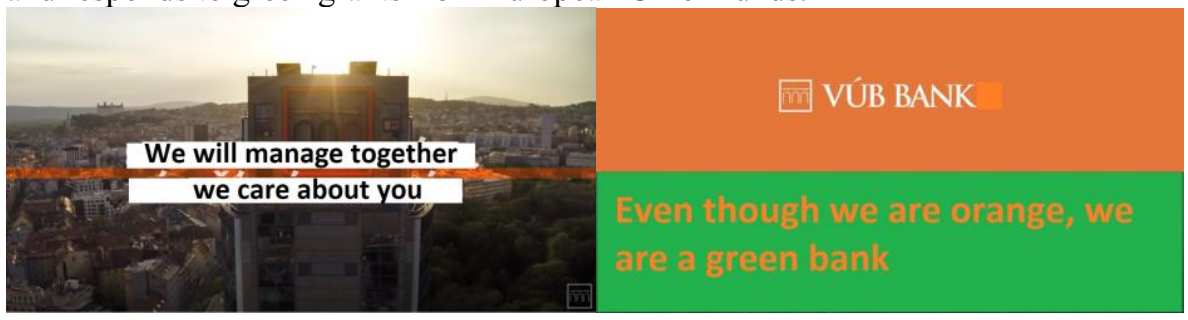


Fig. 4. The second analyzed commercial.

At present, communication has returned to normal before the crisis, focusing its attention on the presentation of environmental grants. This is a topic that Europe as a whole is addressing, because after the crisis, economic recovery is being planned through green grants. The company has not yet responded to the second wave of the pandemic with any adjustments to its advertising strategy.

\section{Conclusion}

We have set two main evaluation criteria. In the first case, we observed a change in consumer behavior in connection with the onset of the crisis period. We found a preference for society-wide interests at the expense of personal interests. We consider this to be very important and a reason to change our advertising strategy. In the second case, we were interested in the opinion of the population in Slovakia. The criterion was to find out to what extent people reject or do not reject advertising in times of crisis. We've evaluated the situation as very favorable, so there's no reason to restrict advertising.

In our opinion, in the current situation, VUB Bank behaved well when it responded to the onset of the crisis with this form of advertising strategy. At the time of writing, Slovakia, but also Europe, is in a dangerous situation again, the second wave of Covid-19 is beginning to show its strength. Many societies, but also entire sectors of the economy, such as sport or culture, are facing existential problems and will therefore face even greater challenges than before. On the one hand, the state must certainly intervene, especially in the case of sole proprietors and small, perhaps medium-sized enterprises, but at the global level there is a new opportunity to prove that social responsibility means more to them than just complying with the law. For the area of advertising that was the subject of our post, we recommend responding to the current situation and closely monitoring changes in consumer behavior. Not every company responds on the basis of surveys or professional studies, so we recommend monitoring the situation and re-evaluating their campaigns more often than in the standard period. The customer changes much faster, so if a company currently fails in advertising, it can lead to customer loss.

\section{References}

1. Murray, A., Skene, K., Haynes, K. (2017). The circular economy: an interdisciplinary exploration of the concept and application in a global context. J. Bus. Ethics, 140(3), 369-380.

2. Babbitt, C.W., Gaustad, G., Fisher, A. (2018). Closing the loop on circular economy research: from theory to practice and back again. Resour. Conserv. Recycl., 135, 1-2. 
3. Hofmann, F. (2019). Circular business models: business approach as driver or obstructer of sustainability transitions? J. Clean. Prod., 224, 361-374.

4. Bednarik, J. (2019). Change of paradigm in personnel strategy - corporate social responsibility and internal communication. Communication Today, 10(2), 4256.

5. Alfredsson, E. Bengtsson, M. (2018). Why achieving the Paris Agreement requires reduced overall consumption and production. Sustain. Sci. Pract. Policy., 14, 1-5.

6. Kantar. (2020). Covid-19 Barometer. Retrieved from http://www.kantar.com/campaigns/covid-19-barometer

7. Butcher, B., Massey J. (2020). Are ethnic minorities being hit hardest by coronavirus? The $B B C$, Retrieved from: https://www.bbc.co.sk/news/uk$\underline{52219070}$

8. Hardingham, E., Vrbka, J., Kliestik, T., Kliestikova, J. (2018). Will cognitive technology-driven automation lead to econoimc growth? Journal of SelfGovernance and Management Economics, 6, 13-18.

9. Fox, M.A. (2018). Drive-in theatres, technology, and cultural change. Economics, Management, and Financial Markets, 13, 24-39.

10. Meila, A.D. (2019). Regulating the sharing economy at the local level: How the technology of online labor platforms can shape the dynamics of urban environments. Geopolitics, History, and International Relations, 10, 181-187.

11. Loucanova, M., Olsiakova, M., Drlickova, E. (2018). Regional marketing and business in context ,act locally“, think globally“. In: Kliestik, T. (Eds.). Globalization and its socio-economic consequences (681-687). Rajecke Teplice: Conference Proceedings.

12. Robinson, A.A., Levac, L. (2018). Tranformative learning in developing as an engaged global citizen. Journal of transformative education, 16, 108-129.

13. Frewer, L. (2004). The public and effective risk communication. Toxicol. Lett.149, 391-397.

14. Arvai, J., Rivers, L. (2014). Effective risk communication. Routledge: London, UK.

15. Kim, W.H., Malek, K. Roberts, K.R. (2019). The effectiveness of green advertising in the convention industry: an application of a dual coding approach and the norm activation model. J.Hosp. Tour. Manag, 39, 185-192.

16. VUB. Retrieved from: https://www.vub.sk/o-banke/profil-banky/\#tab_3

17. VUB. Retrieved from: https://www.vub.sk/spolocenska-zodpovednost/ 